GHÂNCARAN: JURNAL PENDIDIKAN
$\begin{aligned} & \text { BAHASA DAN SASTRA INDONESIA } \\ & \frac{\text { http://ejournal.iainmadura.ac.id/index.php/ghancaran }}{\text { E-ISSN : 2715-9132; P-ISSN: } 2714-8955} \\ & \text { DOI } 10.19105 / \text { ghancaran.vi.5315 }\end{aligned}$

\title{
Cerminan Etika Profetik dalam Novel Di Kaki Bukit Cibalak Karya Ahmad Tohari Sebagai Media Pendidikan Karakter Peduli Sosial Pascapandemi
}

\author{
Fanie Yuniar Krismonita \\ Pendidikan Bahasa Indonesia Pascasarjana Universitas Sebelas Maret \\ Alamat surel: fanieyuniar@student.uns.ac.id
}

\begin{tabular}{|c|c|}
\hline & Abstract: \\
\hline \multirow[t]{2}{*}{$\begin{array}{l}\text { Keywords: } \\
\text { prophetic } \\
\text { ethics, } \\
\text { character } \\
\text { education, } \\
\text { social care }\end{array}$} & $\begin{array}{l}\text { This study aims to describe prophetic ethics in the novel Di Kaki } \\
\text { Bukit Cibalak by Ahmad Tohari as a source of character education. } \\
\text { This study uses a qualitative approach. From the results of the } \\
\text { study, it was found that the ethics of humanization in the novel Di } \\
\text { Kaki Bukit Cibalak covers the personality aspect in the form of not } \\
\text { distinguishing between humans. The liberation ethics of the novel } \\
\text { Di Kaki Bukit Cibalak found include forms of activity that free } \\
\text { oneself and others from political oppression and economic injustice. } \\
\text { The transcendence ethic was found to include a sense of surrender } \\
\text { to God in any situation, namely qanaah and tawakkal. In post- } \\
\text { pandemic situations that still use distance learning, literary works } \\
\text { can be an alternative as a medium for planting character education. } \\
\text { The three aspects contained in the novel Di Kaki Bukit Cibalak can } \\
\text { be used as learning media in instilling the components of social } \\
\text { care education. }\end{array}$ \\
\hline & Abstrak: \\
\hline $\begin{array}{l}\text { Kata Kunci: } \\
\text { etika profetik; } \\
\text { pendidikan karakter; } \\
\text { peduli social. }\end{array}$ & $\begin{array}{l}\text { Penelitian ini bertujuan mendeskripsikan etika profetik pada novel } \\
\text { Di Kaki Bukit Cibalak karya Ahmad Tohari sebagai sumber } \\
\text { pendidikan karakter. Penelitian ini menggunakan pendekatan } \\
\text { kualitatif. Dari hasil penelitian ditemukan etika humanisasi novel } \\
\text { Di Kaki Bukit Cibalak meliputai adanya aspek personalitas berupa } \\
\text { tidak membedakan sesama manusia. Etika liberasi novel Di Kaki } \\
\text { Bukit Cibalak yang ditemukan meliputi bentuk aktivitas yang } \\
\text { membebaskan diri sendiri dan orang lain dari penindasan politik } \\
\text { dan ketidakadilan ekonomi. Etika transendensi ditemukan meliputi } \\
\text { rasa berserah kepada Tuhan dalam situasi apapun yaitu qanaah } \\
\text { dan tawakkal. Pada situasi pascapandemi yang masih } \\
\text { menggunakan pembelajaran jarak jauh, karya sastra dapat menjadi } \\
\text { alternatif sebagai media penanaman pendidikan karakter. Ketiga } \\
\text { aspek yang terdapat dalam novel Di Kaki Bukit Cibalak dapat } \\
\text { dijadikan sebagai media pembelajaran dalam menanamkan } \\
\text { komponen pendikan peduli sosial. }\end{array}$ \\
\hline \multirow[t]{2}{*}{ Terkirim: $15-08-2$} & ; Diterima: 01-11-2021 \\
\hline & $\begin{array}{c}\text { CGhâncaran: Jurnal Pendidikan Bahasa dan Sastra Indonesia } \\
\text { Tadris Bahasa Indonesia } \\
\text { Institut Agama Islam Negeri Madura, Indonesia }\end{array}$ \\
\hline
\end{tabular}




\section{PENDAHULUAN}

Sejak bulan Maret 2020, total masyarakat yang positif Covid-19 di Indonesia hampir mencapai 4.000.000 kasus dan kemungkinan masih akan bertambah. Kondisi tersebut mengharuskan pemerintah Indonesia membuat kebijakan-kebijakan khusus untuk mengatur segala aktivitas masyarakat dan berbagai sektor, salah satu di antaranya adalah sekolah. Sekolah dianggap salah satu tempat untuk menanamkan karakter pada siswa. Akan tetapi, pada situasi pandemi pemerintah membuat aturan mengenai aktivitas belajar di rumah secara daring. Karakter dapat diartikan sebagai bentuk kualitas moral dan mental, serta budi pekerti yang ada dalam diri individu sebagai suatu kepribadian khusus (Hidayatullah, 2010: 13).

Pada pembelajaran daring yang terkesan dipaksakan karena situasi dan kondisi memunculkan berbagai macam masalah yaitu kurangnya efektivitas dalam proses pembelajaran. Kurangnya efektivitas dalam pembelajaran tentu saja berpengaruh pada penanaman karakter pada anak. Tujuan pertama dalam pendidikan karakter ialah memberikan fasilitas berupa penguatan dan pengembangan nilai-nilai tertentu dengan tujuan agar dapat tertanam dalam perilaku anak, pada situasi di sekolah maupun di luar sekolah (Kesuma, 2012 :9). Pembiasaan adab dan penanaman karakter menjadi sangat penting agar siswa bisa membawa dirinya secara mandiri dan penuh tanggung jawab selama pembelajaran daring (Jalalludin, 2020).

Oleh karena itu, salah satu upaya untuk menanamkan pendidikan karakter pada anak pada masa pandemi ialah melalui karya sastra. Pemilihan karya sastra yang bermutu untuk bahan ajar maupun bacaan pada pembelajaran di sekolah memiliki manfaat yaitu sebagai penanaman pendidikan karakter pada anak karena karya sastra pada hakikatnya adalah alat mengajarkan kehidupan, bahkan karya sastra dapat berfungsi sebagai cermin dan jendela pada masyarakat global (Sugiarti, 2018).

Karya sastra merupakan sarana yang dapat digunakan untuk menyampaikan pesan-pesan untuk menjalani pelbagai persoalan kehidupan, misalnya pesan untuk menyampaikan moral, nilai agama, nilai sosial, dan sebagainya. Lahirnya sebuah karya sastra karena adanya tuangan imajinasi dari seorang pengarang yang bertujuan untuk merefleksikan mengenai konflik dan kejadian di sekitarnya. Oleh karena itu, karya sastra dapat dikatakan selalu berkaitan dengan kehidupan masyarakat. Sama halnya dengan yang dijelaskan oleh Nurgiyantoro (2015: 3) bahwa melalui karya sastra pengarang berusaha untuk menyampaikan berbagai macam masalah kehidupan akibat adanya interaksi dengan lingkungan, diri sendiri, dan Tuhan. 
Salah satu bentuk karya sastra dalam bentuk novel ialah novel yang berjudul Di Kaki Bukit Cibalak karya Ahmad Tohari. Novel ini menceritakan tentang kehidupan masyarakat Banyumas. Tokoh sentral pada novel ini yaitu seorang pemuda bernama Pambudi yang berasal dari Desa Tanggir Banyumas. la adalah seorang pemuda yang menjunjung tinggi sikap kemanusiaan antar sesama manusia yang digambarkan ketika Pambudi bersedia membantu Mbok Ralem untuk mengobati kankernya ketika tak ada satupun orang yang bersedia membantu Mbok Ralem. Kemudian, Pambudi memiliki prinsip menghindari kecurangan karena hal tersebut melanggar etika dalam berkehidupan, hal tersebut digambarkan ketika rekan sejawatnya Poyo dan Pak Dirga menjual padi dengan harga sesuka mereka dengan tujuan mendapat keuntungan yang besar, akan tetapi Pambudi merasa hal tersebut tidak pantas dan tidak patut dicontoh sehingga membuat ia mencari keadilan dengan cara menyuarakan keresahannya. Serta pada novel ini juga menggambarkan ketaatan masyarakat Tanggir kepada Tuhan. Gambaran tentang perilaku masyarakat Banyumas yang dituangkan oleh Ahmad Tohar ini sesuai dengan komponen yang dikaji dalam etika profetik yaitu etika humanisasi, etika liberasi dan etika transendensi.

Etika profetik yang dicetuskan oleh Kuntowijoyo ini bersifat untuk memanusiakan manusia. Etika profetik menganalisis 3 bentuk yaitu etika humanisasi, etika liberasi dan etika transendensi (Kuntowijoyo, 2019: 9). Ketiga aspek tersebut menjadi pokok bahasan yang paling utama dalam etika profetik. Ketiga etika tersebut dapat dikatakan memiliki keterkaitan yang sangat erat dengan tujuan menjadikan manusia yang bermartabat dan melepaskan manusia dari belenggu dunia.

Etika humanisasi mempunyai sudut pandang pokok yaitu untuk memanusiakan manusia. Seperti pada kenyataannya bahwa dalam masyarakat memiliki 3 bentuk keadaan yaitu dehumanisasi, agresivitas dan loneliness, oleh karena itu pemahaman mengenai humanisasi sangat diperlukan (Kuntowijoyo, 2019: 10). Selanjutnya, etika liberasi memiliki cara padang untuk membebaskan manusia lain maupun diri sendiri dari ketidakadilan, kekejaman, kemiskinan, pemerasan, serta budaya dominasi. Kemudian etika transendensi dalam ilmu profetik yaitu memiliki kepercayaan penuh atas takdir Tuhannya (Kuntowijoyo, 2019:25).

Nilai-nilai yang terdapat dalam sebuah sastra dipercaya mampu mendorong dan membangun karakter manusia serta berfungsi untuk meningkatkan bentuk kemunduran karakter menjadi lebih baik sekaligus berfungsi pula untuk menjauhkan diri dari hal negatif (Noor, 2011:81). Suatu karya sastra dapat dijadikan sebagai media pendidikan karakter bukan disusun untuk membentuk tingkah laku, melainkan memiliki fungsi agar 
dapat menggugah, membangun, dan menanamkan nilai-nilai karakter yang terdapat pada siswa. Hal tersebut sejalan dengan fungsi etika profetik yaitu bertujuan untuk menumbuhkan kesadaran dalam diri dan pengendalian diri guna mengimbangi permasalahan dalam kehidupan. Sesuai dengan penelitian yang telah dilakukan oleh Wulananda (2016) bahwa etika profetik yang tertuang pada suatu karya sastra layak dijadikan media atau sumber penanaman nilai-nilai dalam pembentukan karakter, sikap, dan perilaku siswa. Kemudian, yang dikatakan Fuadi (2016) bahwa nilai profetik yang dicetuskan oleh Kuntowijoyo menggambarkan proses pendidikan karena humanisasi dapat membangun psikomotorik serta rasa kepedulian sosial. Kemudian, liberasi mengacu untuk mengembangkan akal dan pikiran dan yang terakhir transendensi mengacu pada pendidikan hati nurani karena adanya akidah dan pemahaman spiritual. Oleh karena itu, etika profetik mampu mengembangkan karakter peduli sosial pada siswa.

Berdasarkan konteks dari penelitian yang dijabarkan, penelitian bertujuan untuk untuk mendeskripsikan etika profetik dalam novel Di Kaki Bukit Cibalak karya Ahmad Tohari sebagai media pendidikan karakter yang mencakup (1) etika humanisasi, (2) etika liberasi, dan (3) etika transendensi.

\section{METODE}

Metode deskriptif kualitatif adalah metode yang digunakan dalam penelitian ini. Sutopo (2006:40) memaparkan bahwa metode kualitatif deskriptif adalah metode penelitan yang menganalisis mengenai informasi yang kaya akan makna dan bukan berupa angka. Deskriptif kualitatif merupakan penelitian yang mendeskripsikan dan memahami suatu subjek penelitian misalnya tindakan/perilaku, presepsi dan lain-lain berupa kata, frasa, klausa, dan kalimat.

Objek dalam penelitian ini yaitu novel Di Kaki Bukit Cibalak karya Ahmad Tohari sekaligus sebagai sumber data. Sedangkan data dalam penelitian yaitu bentuk-bentuk berupa dialog maupun narasi yang menunjukan etika profetik pada novel Di Kaki Bukit Cibalak karya Ahmad berupa dialog maupun narasi. Teknik pengumpul data pada penelitian ini menggunakan teknik baca catat dengan cara mengidentifikasi kata-kata maupun kutipan dari narasi, monolog, dan dialog tokoh yang sesuai dengan fokus penelitian, yaitu etika humanisasi, etika liberasi, dan etika transendensi sebagai media pendidikan karakter. Teknik validitas data dalam penelitian ini menggunakan trianggulasi teori. Teknik analisis data dalam penelitian menggunakan model analisis 
Miles dan Huberman (1992:18) yang meliputi tiga alur kegiatan yang terjadi secara bersamaan, yaitu (1) reduksi data, (2) penyajian data, dan (3) penarikan simpulan.

\section{HASIL DAN PEMBAHASAN}

\section{Etika Profetik Humanisasi pada Novel Di Kaki Bukit Cibalak karya Ahmad Tohari}

Humanisasi ialah sebuah bentuk aktivitas berupa perilaku yang menyeimbangkan nilai-nilai kemanusiaan dengan tujuan tidak membedakan manusia dengan berpatokan pada kedudukan ataupun kriteria. Pada novel Di Kaki Bukit Cibalak karya Ahmad Tohari ditemukan berupa manusia yang bersikap dengan didasari oleh akal sehat, nilai, serta norma yang ada di masyarakat tanpa membeda-bedakan status sosial, ditunjukkan pada kutipan di bawah ini:

"Sepantasnya Mbok Ralem diperlakukan secara khusus. la sakit. Wajarlah bila ia diberi pinjaman sebesar yang ia perlukan untuk biaya penyembuhan penyakitnya itu."

Etika humanisasi dapat berupa digambarkannya sebuah karakter yang baik yaitu mengenai suatu pemikiran tokoh untuk memandang situasi tertentu dengan cara melakukan penilaian secara moral. Pada kutipan dialog di atas menggambarkan ketika tokoh bernama Pak Dirga selaku seorang lurah yang memiliki sikap tidak perduli terhadap sesama. Akan tetapi, disangkal oleh tokoh Pambudi bahwa seharusnya sebagai manusia yang kita berkewajiban untuk menolong sesama yaitu menolong dan lebih memperhatikan orang miskin yang sedang mengalami kesulitan seperti Mbok Ralem agar terlepas dari kesusahan yang sedang ia alami tanpa mengukur dari segi status sosial. Perilaku yang ditunjukan oleh Pambudi merupakan bentuk-bentuk ekspresi yang menunjukkan kepedulian antar sesama karena merasa memiliki kewajiban untuk melakukan sesuatu yang benar. Kemudian, sikap-sikap yang menjunjung tinggi nilai humanisme pada diri Pambudi ditunjukkan pada rasa simpati Pambudi pada Mbok Ralem untuk menyembuhkan penyakit Mbok Ralem, dapat dilihat pada dialog yang dilakukan oleh Pambudi dan Mbok Ralem di bawah ini:

"Sambil menangis Mbok Ralem menyerahkan kertas yang digenggamnya kepada Pambudi. Perempuan lugu yang amat miskin itu terharu. Ternyata ada seseorang yang mau menganggapnya sama dengan orang lain, dan mau menolong" (Tohari, 2014:32)

Kutipan di atas menggambar kan perbuatan yang dilakukan oleh seseorang pemuda bernama Pambudi yang dengan ikhlas memberi atau menolong seseorang 
tanpa meminta balas budi dan tanpa pamrih yang diberikan pada Mbok Ralem. Selama ini Mbok Ralem yang selalu dipandang sebelah mata dan tidak diperdulikan penyakit yang diidapnya. Akan tetapi, sikap Pambudi menggambarkan pria yang rendah hati bersedia tetap membantu tanpa imbalan apapun. Pambudi bersikap empati dan menolong Mbok Ralem hanya atas dasar kemanusiaan tanpa menimbang perihal apapun. Sikap empati Pambudi tersebut mencerminkan sikap humanisme. Humanisasi dalam pandangan profetik juga berupa merawat sesama pada lingkungan yang sama dan terus berusaha berbuat kebaikan antar individu. Empati merupakan suatu bentuk upaya individu untuk membayangkan keadaan yang dialami oleh orang lain, kemudian terjadi kepekaan dari diri individu tersebut untuk memberikan bantuan kepada orang lain yang berada pada keadaan sulit (Syueb, 2006: 110). Selain perilaku Pambudi, perawat-perawat di rumah sakitpun menggambarkan bentuk memanusiakan manusia. Dapat dilihat pada kutipan di bawah ini:

\footnotetext{
"Seorang seperti Mbok Ralem dimandikan oleh perawat yang cantik-cantik, memakai sabun entah apa namanya yang wanginya belum pernah masuk ke hidung perempuan dusun itu. Wah, handuk itu putih, lebih putih dari ampas kelapa. Mbok Ralem merasa seolah-oleh sedang bermimpi” (Tohari, 2014:49)
}

Kutipan di atas mengilustrasikan etika humanisme melalui perlakuan para perawat kepada Mbok Ralem. Para perawat yang tetap memperlakukan Mbok Ralem sebagaimana mestinya merupakan penerapan sikap humanisme berupa sebagai sesama manusia harus yang harus saling menghargai serta saling menjaga tanpa melihat darimana asal Mbok Ralem dan penampilan Mbok Ralem. Humanisasi adalah representasi dari nilai yang tertanam dalam masyarakat untuk menghilangkan sifat membedakan, kekerasan dan kebencian (Kuntowijoyo, 2019: 10).

\section{Etika Profetik Liberasi pada Novel Di Kaki Bukit Cibalak karya Ahmad Tohari}

Liberasi ialah sebuah upaya yang dilakukan oleh seseorang dengan tujuan agar dapat membebaskan manusia dari sifatnya karena terbelenggu atas dunia. Contohnya membebaskan manusia lain maupun diri sendiri dari kesenjangan atas sistem sosial, ekonomi, politik, maupun pengetahuan. Pada novel Di Kaki Bukit Cibalak karya Ahmad Tohari ditemukan etika liberasi berupa bentuk penindasan dan ketidakadilan pada sistem ekonomi, politik, dan sosial. Ditunjukan pada kutipan di bawah ini:

"Mereka dapat mencantumkan harga penjualan semau mereka sendiri, dan dari tengkulak padi mereka mendapat semacam komisi. Pambudi tahu, sama sekali 
tidak sukar berbuat demikian karena badan koperasi itu tanpa pengawasan, apa lagi penelitian. Dan, kebanyakan penduduk Tanggir adalah anak-cucu kaum kawula. Mereka 'nrimo', sangat 'nrimo'."(Tohari, 2014:18)

Kutipan di atas mengilustrasikan tentang kecurangan yang dilakukan oleh lurah Desa Tanggir bernama Pak Dirga dengan cara menaikkan harga sembako semau hatinya demi mendapatkan untung berlipat ganda. Pak Dirga melakukan hal tersebut karena ia mengetahui bahwa masyarakat Banyumas khususnya di Desa Tanggir memiliki sikap nrimo atau menerima dan pasrah. Meskipun demikian, Pambudi sebagai penjaga koperasi tidak berniat sedikitpun mengikuti jejak Pak Dirga meskipun memiliki kesempatan yang sama. Pambudi menyadari bahwa hal tersebut bertentangan dengan norma yang ada di masyarakat. Perilaku Pambudi merupakan langkah pertama sebagai upaya dalam membebaskan dan memerdekakan orang lain dari ketidakadilan. Kutipan di atas merepresentasikan bentuk pendidikan karakter jujur dan adil, komponen karakter tersebut diterapkan di dalam novel dengan tujuan meningkatkan rasa peduli antar sesama. Kemudian, etika liberasi berupa upaya untuk membebaskan manusia dari masalah yang membelenggu manusia karena adanya perbedaan status sosial yaitu kemiskinan, tergambar pada kutipan di bawah ini:

"Kali ini saya harus tau. Soalnya, saya ingin tahu, penting mana rencana Bapak itu dengan keharusan kita menolong Mbok Ralem. Maaf, Pak, sesungguhnya saya merasa masygul. Untuk membiayai pelantikan Bapak beberapa bulan yang lalu, kas dana darurat susut 125.000 rupiah. Sebaliknya Bapak tidak merelakan sedikitpun uang dana darurat itu untuk menolong Mbok Ralem" (Tohari, 2014:2324)

Kutipan di atas merupakan dialog antar tokoh yang mengilustrasikan mengenai sebuah tuntutan keadilan. Pak Dirga yang digambarkan seorang yang hidupnya melulu akan politik dan kepentingan dirinya sendiri tanpa menghiraukan orang lain. Akan tetapi, Pambudi berusaha untuk menegakkan keadilan dengan mengkritik Pak Dirga karena telah melakukan kecurangan pada saat pelantikannya menjadi lurah. Di samping itu, Pambudi melakukan hal tersebut bertujuan untuk membantu Mbok Ralem. Pambudi berusaha cara menyelesaikan satu konflik dengan pandangan yang adil sehingga keputusan dapat diterima semua pihak. Selain itu, pada novel Di Kaki Bukit Cibalak karya Ahmad Tohari ini juga mengandung upaya pembebasan diri dari sistem sosial. Tergambar pada kutipan di bawah ini:

"Ini pasti perbuatan Lurah Tanggir dan Poyo. Pengecut! Akan kubuktikan di depan pengadilan siapa yang menggarong uang itu. Penduduk Tanggir harus yakin 
bahwa aku masih tetap Pambudi yang dulu, yang menganggap kejujuran adalah hal yang wajar yang harus dihormati semua orang." (Tohari, 2014:115)

Kutipan di atas adalah dialog yang diucapkan oleh Pambudi ketika ia mengetahui bahwa ia dituduh mengambil uang koperasi. Hal tersebut terbelenggunya Pambudi secara sosial yaitu namanya dikenal buruk. Akan tetapi, Pambudi berusaha untuk melawan penindasan tersebut dengan tidak putus asa dan berupaya agar masyarakat kembali mempercayai dirinya bahwa ia adalah orang yang jujur dan tidak pernah sekalipun mengambil yang bukan haknya. Abidin (2006:40) mengatakan bahwa penanaman sikap liberasi maka akan menjadikan manusia memiliki prinsip yaitu sebagai makhluk bebas dan berkuasa penuh sehingga dapat mematahkan pengaruh dari luar yang bermaksud membelenggu kebebasan manusia.

\section{Etika Profetik Transendensi pada Novel Di Kaki Bukit Cibalak karya Ahmad Tohari}

Etika transendensi memandang hubungan manusia dengan Tuhannya. Manusia sebagai entitas yang lemah dan selalu bergantung pada Tuhannya. Pada novel Di Kaki Bukit Cibalak karya Ahmad Tohari ditemukan etika transendensi berupa rasa syukur dan tawakkal kepada Tuhan. Ditunjukkan pada kutipan di bawah ini:

"Setelah bersembahyang di atas sehelai koran, Pambudi merebahkan diri hendak tidur. Sebelumnya ia menyalakan obat pengusir nyamuk yang ia beli sendiri." (Tohari, 2014:40)

Kutipan di atas mengilustrasikan etika transendensi berupa sifat qanaah. Sifat qanaah yang digambarkan dalam novel ini adalah menerima segala yang diberikan oleh Allah kepada umatnya dengan cara senantiasa mensyukuri nikmat-Nya dan selalu mengingat-Nya. Pambudi yang tetap melaksanakan ibadah meskipun hanya beralaskan selembar koran merupakan gambaran bahwa Pambudi senantiasa mengingat Tuhan di manapun dan bagaimanapun situasinya. Sikap qanaah pada diri seseorang akan membuat ia mempersiapkan diri di akhirat (Hamid, 1994:164).

Pada novel Di Kaki Bukit Cibalak karya Ahmad Tohari ini menggambarkan sikap penuh harap atau raja'. Manusia memiliki sifat raja' karena manusia adalah makhluk yang senantiasa berharap dan meminta sesuatu kepada Tuhannya. Karena hanya pada Tuhanlah, manusia menggantungkan harapan. Hal ini tergambar pada sikap ayah Pambudi, dapat dilihat pada kutipan di bawah ini: 
"Orang tua itu mencari penawar kebimbangannya dengan duduk dan bersujud kepada Tuhan sampai menjelang Fajar, ayah Pambudi belum melepaskan doanya." (Tohari, 2014:77)

Pada kutipan di atas mengilustrasikan mengenai sikap raja' atau penuh harapan yang digambarkan oleh ayah Pambudi. Ayah Pambudi sangat berharap kepada Tuhannya agar anaknya dapat terbebas dari fitnah kejam dari Lurah Tanggir. Ayah Pambudi merasa hanya kepada Tuhannya ia dapat meminta dan mengharapkan sesuatu, karena Tuhanlah yang menentukan segala jalan hidup dan takdir manusia. Rasa bimbang yang dialami oleh ayah Pambudi membuat ia bersujud hingga Fajar berharap bahwa Tuhan akan memberikan petunjuk bagi keluarganya atas masalah yang sedang keluarganya alami. Keyakinan yang dimiliki seseorang adalah elemen paling penting dalam kehidupan karena keyakinan membuat seseorang menjadi religius dan mempercayai Tuhan (Hill, 2009: 47).

\section{PENUTUP}

Berdasarkan hasil analisis data dan pembahasan menunjukkan bahwa novel $D i$ Kaki Bukit Cibalak karya Ahmad Tohari mengandung etika profetik. Sehingga karya sastra yang mengandung etika profetik dapat dijadikan sebagai media dalam pendidikan karakter yang dapat membantu peserta didik dalam menggugah, membangun, dan menanamkan nilai-nilai karakter memahami nilai-nilai karakter yang ada dalam dirinya. Melalui pembacaan karya sastra dapat membangun nilai karakter pada siswa di masa pascapandemi yang tidak dapat dilakukan di sekolah. Hal tersebut ditunjukkan dengan komponen karakter yang terdapat pada novel Di Kaki Bukit Cibalak karya Ahmad Tohari yang terdapat tiga aspek etika profetik, yaitu (1) humanisasi, (2) liberasi, dan (3) transendensi. Ketiga aspek tersebut cenderung merepresentasikan komponen karakter peduli sosial. Secara sepintas etika profetik dianggap membahas mengenai keagamaan, akan tetapi ketika ditelisik lebih dalam etika profetik lebih mengarah kepada permasalahan sosial.

Pertama, etika profetik humasnisme dalam novel Di Kaki Bukit Cibalak menggambarkan manusia yang memanusiakan manusia lain melalui aspek personalitas yang digambarkan dengan tidak membedakan sesama manusia. Novel Di Kaki Bukit Cibalak mengilustrasikan kesenjangan yang dilakukan oleh manusia, akan tetapi digambarkan pula sikap toleransi untuk memperlihatkan nilai kemanusiaan. Kedua, etika profetik liberasi dalam novel Di Kaki Bukit Cibalak ketika digambarkan manusia yang mulai membelenggu manusia lain pada sistem politik, sosial, dan ekonomi. Liberasi pada novel Di Kaki Bukit Cibalak muncul sebagai upaya seorang 
manusia untuk tidak terjebak pada masalah duniawinya. Manusia yang belum dapat bebas dari masalah di lingkungannya lah yang mendasari liberasi dalam novel Di Kaki Bukit Cibalak. Ketiga, etika profetik transendensi dalam novel Di Kaki Bukit Cibalak digambarkan melalui aktivitas yang dilakukan tokoh yang memperlihatkan aktivitas kerohanian. Transendensi yang digambarkan tokoh berupa sifat qanaah (menerima segala sesuatu), dan sifat raja' (penuh harap) kepada Tuhan.

\section{REFERENSI}

Abidin, Z. 2006. Filsafat Manusia: Memahami Manusia melalui Filsafat. Bandung: Remaja Rosdakarya

Fuadi, H. 2016. Aktualisasi Nilai-nilai Profetik Kuntowijoyo di dalam Pendidikan (Studi Kasus di SMP Birrul Walidain Muhammadiyah Sragen). Tajdida: Jurnal Pemikiran Dan Gerakan Muhammadiyah, 14(2), 18-30.

Hamid, A. 1994. Syekh Yusuf Muhammad: Seorang Ulama, Sufi, dan Pejuang. Jakarta: Yayasan Obor Indonesia

Hidayatullah, Furqon. 2010. Pendidikan Karakter: Membangun Peradaban Bangsa. Surakarta: Yuma Pustaka.

Hill, N. 2009. Think and Grow Rich. Jakarta: Gramedia Pustaka Utama.

Jalalludin, M. 2020.. Nilai Profetik dalam Kumpulan Cerpen Pelajaran Pertama Bagi Calon Politisi Karya Kuntowijoyo Sebagai Bentuk Ekspresi Pendidikan Karakter di Masa Pandemi. In Prosiding Seminar Nasional Bahasa dan Sastra Indonesia (SENASBASA) (Vol. 4, No. 1).

Kesuma, C. T. \& J. P. 2012. Pendidikan Karakter Kajian Teori dan Praktik di Sekolah. Bandung: Remaja Rosdakarya.

Kuntowijoyo. 2013. Maklumat Sastra Profetik. Yogyakarta: CV. Centra Grafindo.

Miles, M. B. \& Huberman, A. M. 1992. Analisis Data Kualitatif: Buku Sumber Tentang Metode-metode Baru. Terjemahan oleh Tjejep Rohendi Rohidi. Jakarta: Universitas Indonesia Press

Noor, R. M. 2011. Pendidikan Karakter Berbasis Sastra: Solusi Pendidikan Moral yang Efektif. Yogyakarta: Ar-Ruzz Media.

Nurgiyantoro, B. 2015. Teori Pengkajian Fiksi. Yogyakarta: Gadjah Mada University Press

Sugiarti, S. 2018. Ekologi Budaya Dalam Sastra Sebagai Pembentuk Karakter Peserta Didik. In Prosiding Seminar Nasional Bahasa dan Sastra Indonesia (SENASBASA) (Vol. 1, No. 1).

Sutopo, H. B. 2006. Metodologi Penelitian Kualitatif: Dasar Teori dan Terapannya dalam Penelitian. Surakarta: Universitas Negeri Sebelas Maret.

Syueb, S. 2006. Buku Pintar Agama Islam. Yogyakarta: Deltamedia.

Wulananda, R., Saryono, D., \& Suwignyo, H. 2016. Estetika profetik novel Muhammad: Lelaki Penggenggam Hujan karya Tasaro GK sebagai sumber pendidikan karakter. Jurnal Pendidikan: Teori, Penelitian, dan Pengembangan, 1(7), 13501363. 